\title{
New development of Pasteurised Roselle (Hibiscus sabdariffa L. 'UKMR-2) pickles
}

\author{
Roshita Ibrahim ${ }^{1}$, Goh Yoke Hoon ${ }^{2}$, Mohd Nizam Lani ${ }^{2 *}$ \\ ${ }^{1}$ School of Engineering Technology, Universiti Malaysia Perlis (UNIMAP), Malaysia \\ ${ }^{2}$ School of Food Science and Technology, Universiti Malaysia Terengganu (UMT), Malaysia
}

\begin{abstract}
The limited utilization of roselle in food products had encouraged this study to be done. This study was conducted to develop the most acceptable pickling formulation for roselle pickles. Sensory evaluation was conducted on six pickling formulations which involved different concentration of sugar (30, 40 and $50{ }^{\circ}$ Brix) and acidity (0.5 and 1.0\%). Sensory attributes evaluated were colour, aroma, texture, sweetness and sourness, and overall acceptability. The formulation $C\left(50{ }^{\circ}\right.$ Brix, $0.5 \%$ acidity) was the best formulation in terms of texture and it was used for preparation of fresh pasteurized, fresh unpasteurized, stored pasteurized and stored unpasteurized pickles, and then proceeded with physico-chemical (pH, ascorbic acid, anthocyanin, energy, ash, fiber, protein, and texture) and microbiological analysis. From fresh calyces to pickles, there were significant increased $(p<0.05)$ in the $p H$ and ash content, significant reduced $(p<0.05)$ in anthocyanin, crude fiber, ascorbic acid and texture, and no significant differences $(p>0.05)$ in energy and protein content. Microbial counts found in all samples were under safe limit. Since there are not much difference in the physico-chemical and microbiological properties of pasteurized and unpasteurized roselle pickles, for both fresh and stored, therefore pasteurization process is not a necessary step in the production of roselle pickles.
\end{abstract}

Keywords: Microbiological properties, pasteurized pickles, physico-chemical characteristics, Roselle (Hibiscus sabdariffa L.), sensory acceptability

\section{Introduction}

Roselle (Hibiscus sabdariffa L.) belongs to Malvaceae family, similar to the national flower Hibiscus, lady fingers and kenaf. Locally, roselle is known as "asam paya", "asam susur", and "asam kumbang" (Musa et al., 2006). Roselle was believed to come from continental of Asia. Despite, it is commercially planted in other tropical countries such as Africa, West Indies and Central America. In Malaysia, roselle was first introduced in the state of Terengganu at the year of 1993 for commercial purposes. It is also planted in the states of Kelantan, Pahang, Selangor, Johor and Sarawak.

Roselle can be considered to be significant source of vitamin C and also fair source of vitamin A (Wong et al 2002). Roselle can be used as a source of strong water-stable and lipid-stable antioxidant including vitamin E (Muhamed et al, 2007). Every parts of roselle including seeds, leaves, fruits and roots are used in various foods products (Qi et al, 2005). In Malaysia, roselle products that have been developed are juice, jam, jelly, puree, cordial, and preserve. However, these products are not very well commercialised. Until now very little information has been generated on the other potential products from roselle such as roselle pickles.

According to Malaysia Food Regulation 1985, pickles shall be the clean, sound vegetable or clean, sound fruit or a combination of these, preserved in salt, vinegar, citric acid, fumaric acid, lactic acid, malic acid, tartaric acid or any combination of these, with or without nut, sugar and spice. It may be dried. It may contain permitted preservative, colouring, flavouring and food conditioner. Pickling is done by soaking in brine containing salt and acid, resulting being stable for months (Tucker, 2008). Pickled products are made from many different fruits and vegetables such as cucumber, olives, cabbages, pepper, asparagus, green tomatoes, okra, carrots, mangoes and etc (Valdez-Fragoso et al., 2009; Lau and Tang, 2002; Tassou et al, 2002). Sweet pickles are cured pickles that are packed in vinegar solution with suitable nutritive sweetening ingredient(s) (Hui, 2004).

Pasteurization process may destroy spoilage microorganisms and prohibit fermentation from occurring (Barrett, 1993). Jars sealed and heated in water until the temperature at the center of the container reaches $74^{\circ} \mathrm{C}$, maintained 15 minutes, rapidly lowered to $38^{\circ} \mathrm{C}$ (Etchells and Jones, 1944). Pasteurized pickles permit the use of less vinegar and sugar. It also maintains quality, retain firmness and retain flavor (Etchells and Jones, 1944). Therefore the development of pasteurized roselle pickles is a new creation of product from roselle which could preserve and extend the shelf life of roselle.

Recently, there is a study by Nasution et al. 2013 had reported that when proper postharvest treatment was applied, green roselle has potential to be processed into food products such as pickles. Based on their study, anti-browning treatment with $0.15 \mathrm{M}$ calcium chloride was found to produce green roselle (Hibiscus sabdariffa L. 'UKMR-3') pickles with the highest firmness and greenness level, a desirable sensory acceptance, as well as comparatively high vitamin $\mathrm{C}$ content. However, there was no study has been published regarding the 
development of red roselle (Hibiscus sabdariffa L. 'UKMR-2) although the petals of this kind of roselle species has been known for beverage in various ceremonies in West Africa (Pacome et al. 2014).

This study was carried out to determine the sugar and vinegar concentration that are the most acceptable in the development of pasteurised roselle pickles as well as to determine the physico-chemical changes and microbiological properties of fresh roselle, pasteurized, and unpasteurized roselle pickles right after pickling and after one year of storage at room temperature.

\subsection{Materials}

\section{Materials and methods}

The fresh roselle calyces, variety UMKL was obtained from UMT research plot in Rhu Tapai, Setiu, Terengganu. All ingredients used for pickling (salt, sugar, vinegar, calcium) were from the food grade. All the chemicals used for the analyses were of analytical grade and all the microbiological media were from Merck.

\subsection{Pickling procedures}

The freshly harvested roselle calyces were decored, cut into individual sepals and washed with chlorinated water. The calyces were then soaked in salt solution for 3 days before drained and filled into glass jars. The jars were then filled with heavy syrup containing sugar $\left(30,40\right.$ and $\left.50^{\circ} \mathrm{Brix}\right)$, acetic acid $(0.5$ and $1.0 \%$ ) and calcium. For pasteurization process, the jars were then exhausted in boiling water bath until the temperature in the middle of the jar reach $74^{\circ} \mathrm{C}$. The jars were then closed and immersed in boiling water for 15 min followed by tempering with luke warm water for $30 \mathrm{sec}$ and then cooled under running tap water. The roselle calyces in the syrup were then left for one week to be pickled before analyses.

\subsection{Sensory evaluation}

The most acceptable formulation of the pasteurized roselle pickle was determined by the sensory evaluation of acceptance test using 7 hedonic scales (1-disliked extremely to 7-like extremely) by 30 untrained panelists. Sensory attributes evaluated were colour, aroma, texture, sweetness and sourness, and overall acceptability.

\subsection{Physico-chemical Analyses}

(i) Texture: the crunchiness of the roselle pickle was determined by using TA.XTplus Texture Analyser from Stable Macro System with P2N needle probe.

(ii) $\mathrm{pH}$ : the $\mathrm{pH}$ of pickle solution and pickled roselle calyces were determined using digital $\mathrm{pH}$ meter.

(iii) Anthocyanin content: the amount of anthocyanin in the fresh and pickled roselle calyces were determined at $520 \mathrm{~nm}$ using spectrophotometer based on delphinidin-3-glucoside.

(iv) Ascorbic acid: the amount of ascorbic acid were determined according to Jagota and Dani (1982) method using Folin reagent and absorbance at 760nm.

(v) Ash: weighted samples were dried in an oven and burnt in muffle furnace at $550^{\circ} \mathrm{C}$ for at least $6 \mathrm{hr}$.

(vi) Crude fiber: determination of crude fiber in fresh and pickled roselles were done using Fibertec 2021 FiberCap ${ }^{\mathrm{TM}}$ System.

(vii) Protein: determination of protein in fresh and pickled roselles were done based on Kjeldahl method (AOAC, 2000) using Kjeltec system.

(viii) Energy: the energy (KJ) was determined using bomb calorimeter AC-350 (LECO) procedures.

\subsection{Microbiological properties}

The microbial analyses were done on both fresh and pickled samples at $10^{-1}$ to $10^{-3}$ dilutions using pour-plate methods on PCA for aerobic plate count, PDA for yeast and mould count, VRBD for Enterobacteriaceae count, BPA for Staphylococcus aureus count and also MPN for coliform count (Bell et al., 2005).

\subsection{The most acceptable formulation}

\section{Results and discussion}

Among all the 6 formulations of varying amount of sugar and acetic acid, formula B,C and F are more acceptable in taste and overall acceptability attributes, however the texture attribute of formula $\mathrm{C}$ stands up which made it the most acceptable formulation (Fig. 1, 2 and 3). In addition, the texture analysis using texture analyzer also confirmed that formula $\mathrm{C}\left(50^{\circ}\right.$ brix, $0.5 \%$ acidity $)$ was the most acceptable formulation for roselle pickle (Fig. 4). 


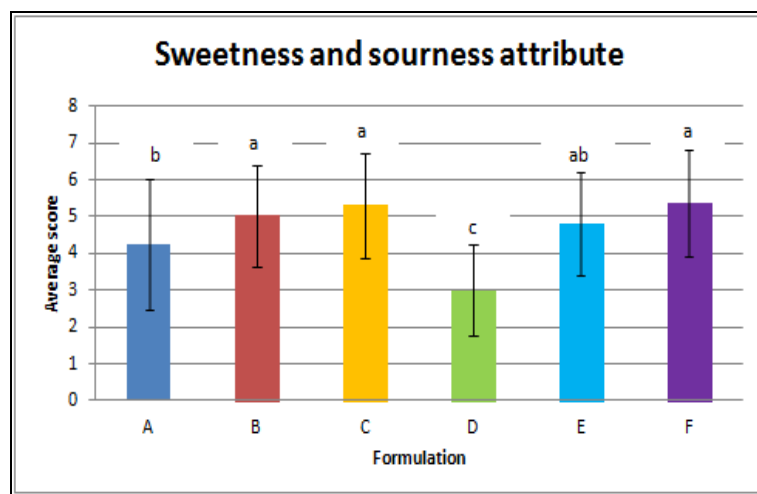

Fig. 1: Taste attribute of different formulation of pasteurized roselle pickles

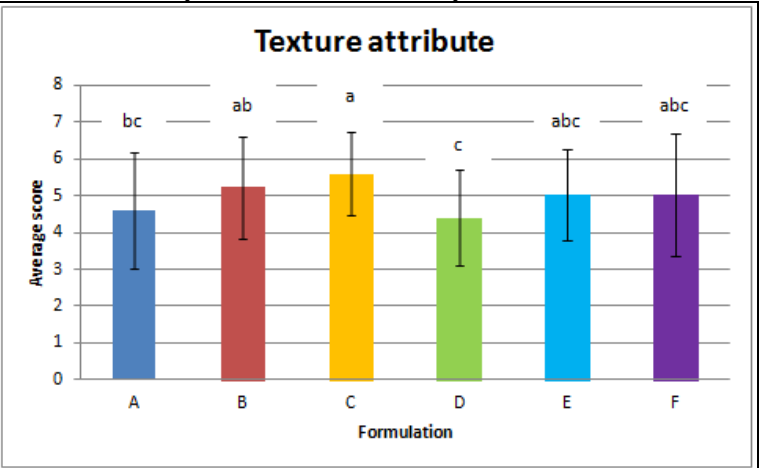

Fig. 3: Texture attribute of different formulation of pasteurized roselle pickles

* Means with the same letter are not significantly different $(\mathrm{p}>0.05)$

* $\mathrm{A}=30 / 0.5, \mathrm{~B}=40 / 0.5, \mathrm{C}=50 / 0.5, \mathrm{D}=30 / 1.0, \mathrm{E}=40 / 1.0, \mathrm{~F}=50 / 1.0$

\subsection{Texture}

There was significant different $(\mathrm{P}<0.05)$ between fresh calyces and pickles. Heat treatment during pasteurization process reduced the texture (Rodrigo and Alvarruiz, 1988) (Fig. 5(a)). Fig. 5(b) also showed significant reduction in texture in stored pickles for both pasteurized and unpasteurized pickles respectively. Acidic condition increased the pectin hydrolysis over the storage (Gu et al. 1999).

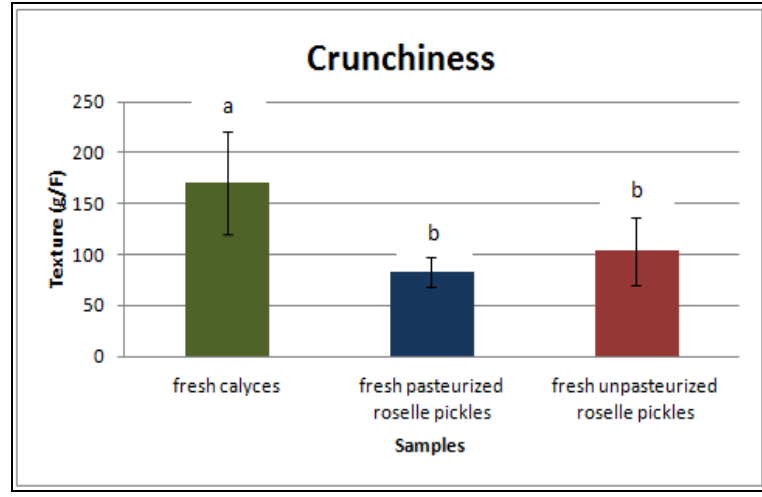

Fig. 5(a): Texture attribute of different formulation of pasteurized roselle pickles

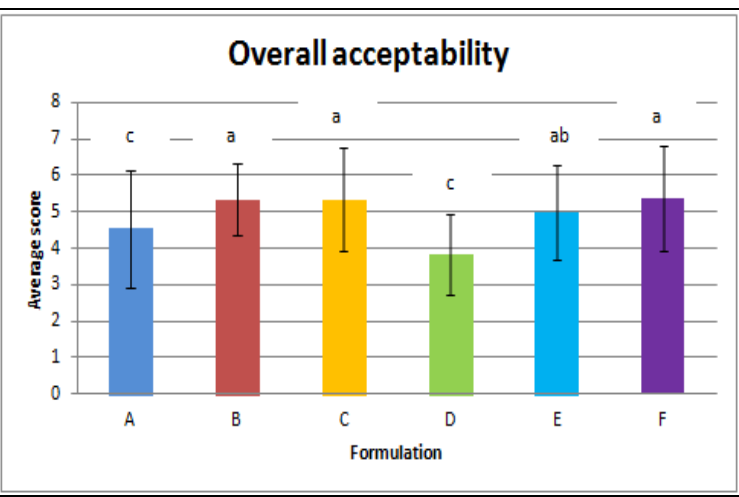

Fig. 2: Overall acceptability of different formulation of pasteurized roselle pickles

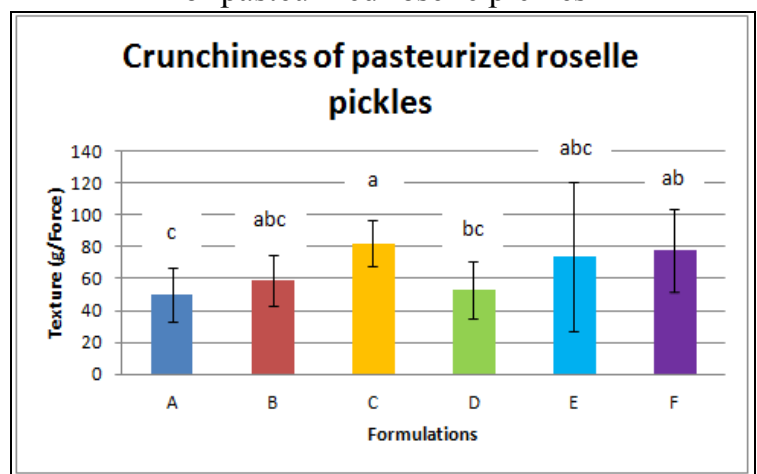

Fig. 4: Texture analysis of different formulation of pasteurized roselle pickles

* Means with the same letter are not significantly different $(\mathrm{p}>0.05)$

\section{$3.3 \mathrm{pH}$}

$\mathrm{pH}$ of fresh roselle calyces was between 2.9 to 3.1. The increased in $\mathrm{pH}$ in roselle pickles was because pickles and pickling solution reached equilibrium during pickling process. Acid food has equilibrium $\mathrm{pH} 4.6 \mathrm{or}$ below (Anon, 2007). Significant different was observed between fresh pasteurized and other pickles (Fig. 6(a) and (b)). Pasteurization permits the use of less vinegar in brined sweet pickles (Etchells and Jones, 1944). Recommended values for pickled vegetables are pH 3.3 - 3.5 (Valdez-Fragoso et al., 2009). 


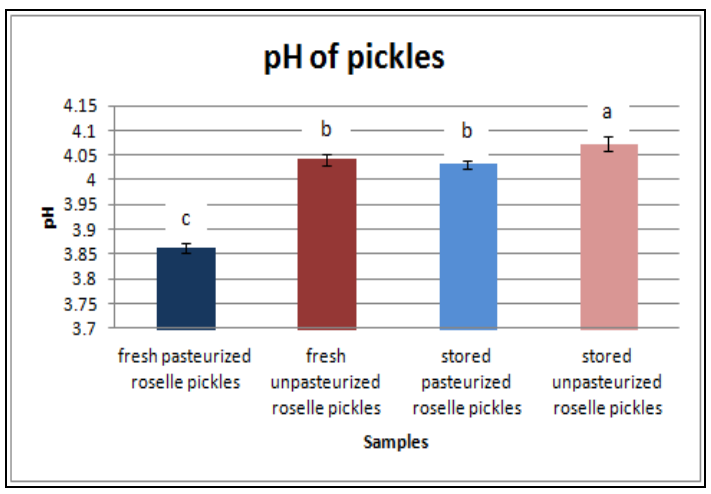

Fig. 6(a): $\mathrm{pH}$ of fresh and stored pickles

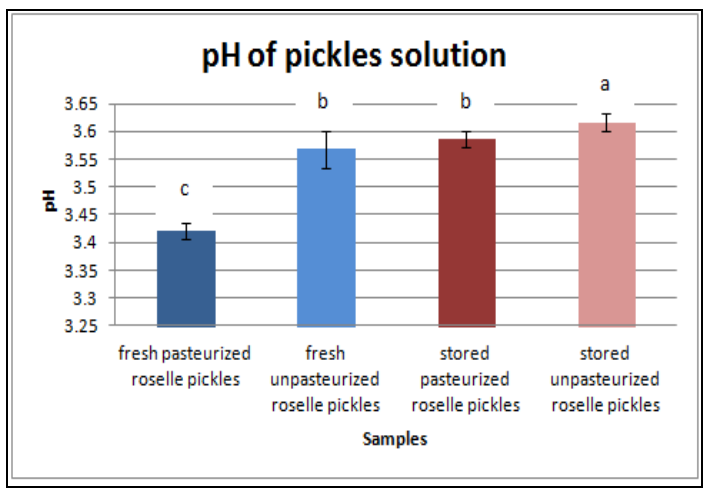

Fig. 6(b): $\mathrm{pH}$ of pickles solution

* Means with the same letter are not significantly different $(p>0.05)$

\subsection{Anthocyanin}

There was significant different $(\mathrm{p}<0.05)$ between fresh calyces and pickles (Fig. 7(a)). Total anthocyanin for fresh roselle is $2.52 \pm 0.05 \mathrm{~g} / 100 \mathrm{~g}$ (Wong et al., 2002). Fig. 7(b) shows significant loss in anthocyanin in stored pickles for both pasteurized and unpasteurized pickles (Fig. 7(b)). Anthocyanin lost due to exposure to light, heat and soluble in pickles solution during storage (Castaneda-Ovando et al., 2009; Osman, 1983).

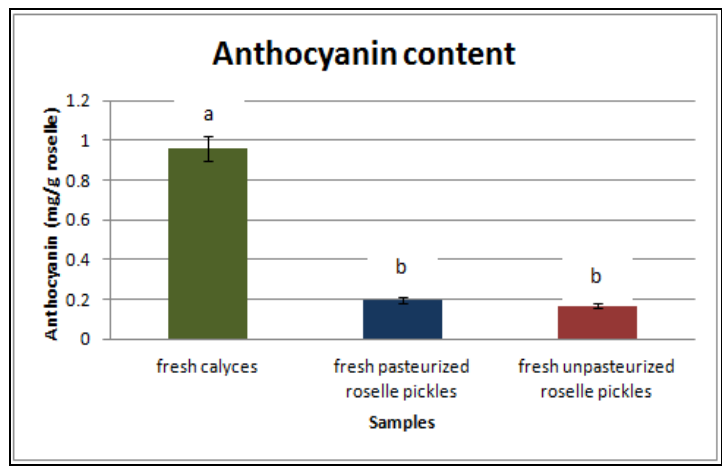

Fig. 7(a): Anthocyanin content of roselle and fresh pickles

* Means with the same letter are not significantly different $(\mathrm{p}>0.05)$

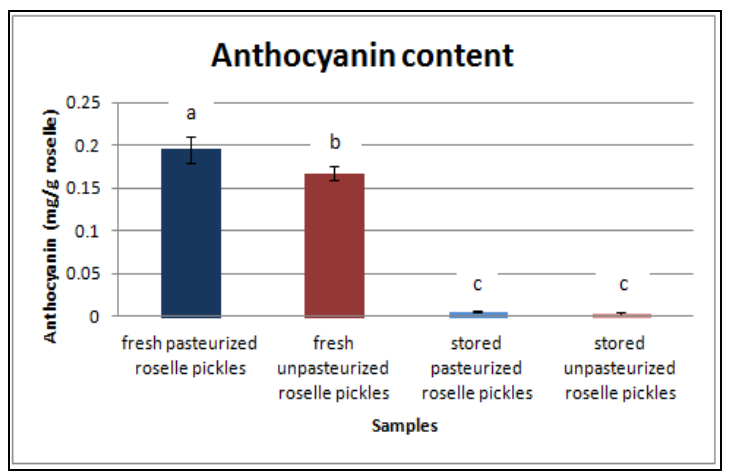

Fig. 7(b): Anthocyanin content of fresh and stored pickles

\subsection{Ascorbic acid}

From Fig. 8(a), there was significant different $(\mathrm{P}<0.05)$ between fresh calyces and fresh unpasteurized pickles. Total ascorbic acid for fresh calyx is $141.09 \pm 22.54 \mathrm{mg} / 100 \mathrm{~g}$ roselle (Wong et al., 2002). Fig. 8(b) shows significant different between fresh pickles (pasteurized and unpasteurized). Pasteurization removed oxygen that will react with ascorbic acid therefore resulted in significant different in ascorbic acid content between fresh and stored pickles respectively. Ascorbic acid lost was due to the exposure to light and also soluble in pickle solution over the storage.

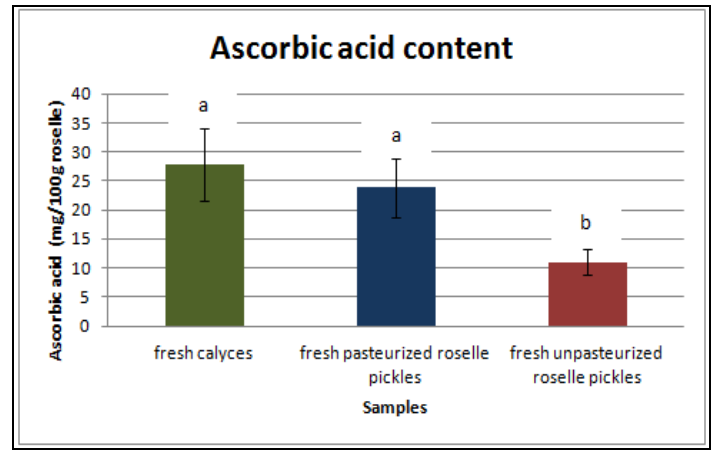

Fig. 8(a): Ascorbic acid content of roselle and fresh pickles

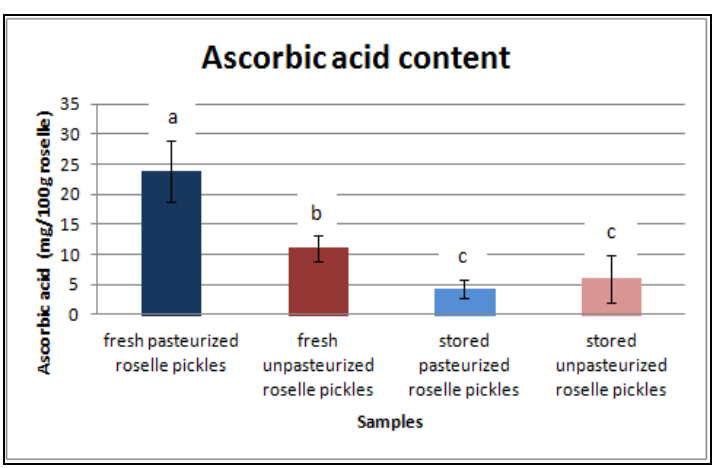

Fig. 8(b): Ascorbic acid content of fresh and stored pickles

* Means with the same letter are not significantly different $(p>0.05)$ 
Fig. 9(a) shows significant different between fresh calyces and fresh pickles. This might be due to the addition of ingredients like sugar, vinegar, calcium lactate and salt in the pickles. Ash content in fresh roselle was reported to be $6.9 \mathrm{~g} / 100 \mathrm{~g}$ (Musa et al. 2006). Ash content in sweet cucumber pickles was $1.7 \mathrm{~g} / 100 \mathrm{~g}$ (Barrett, 1993). Fig. 9(b) shows the ash content in pasteurized roselle pickles reduced significantly over the storage. More minerals were leaching into the pickle solution due to the destruction of cell wall due to pasteurization and increase in the hydrolysis of pectic cell wall over the storage.

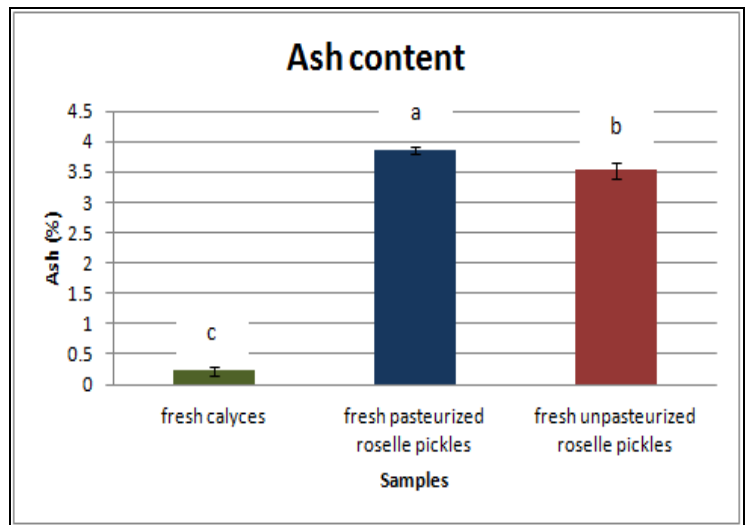

Fig. 9(a): Ash content of roselle and fresh pickles

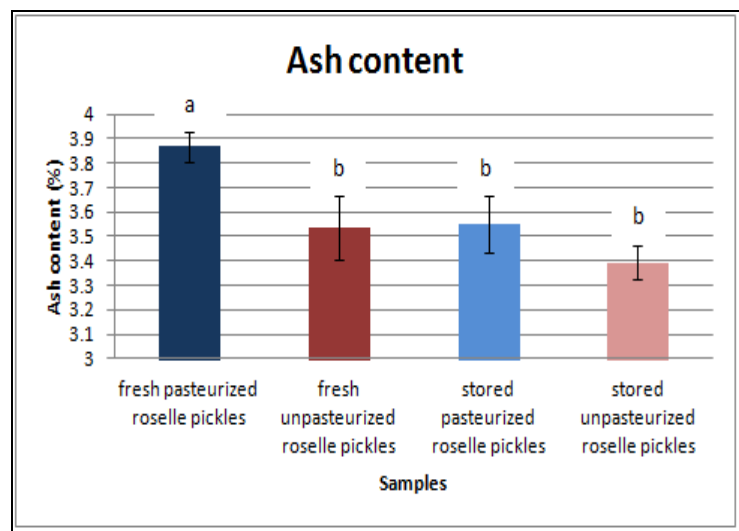

Fig. 9(b): Ash content of fresh and stored pickles

\subsection{Crude fiber}

* Means with the same letter are not significantly different $(p>0.05)$

Fig. 10(a) shows significant different between fresh calyces and pickles. Soluble fiber dissolved in pickling solution. Fiber content in fresh roselle was reported to be 12g/100g (Musa et al. 2006). Fig. 10(b) also shows significant reduction in stored unpasteurized pickles. Most probably fiber was degraded by bacteria.

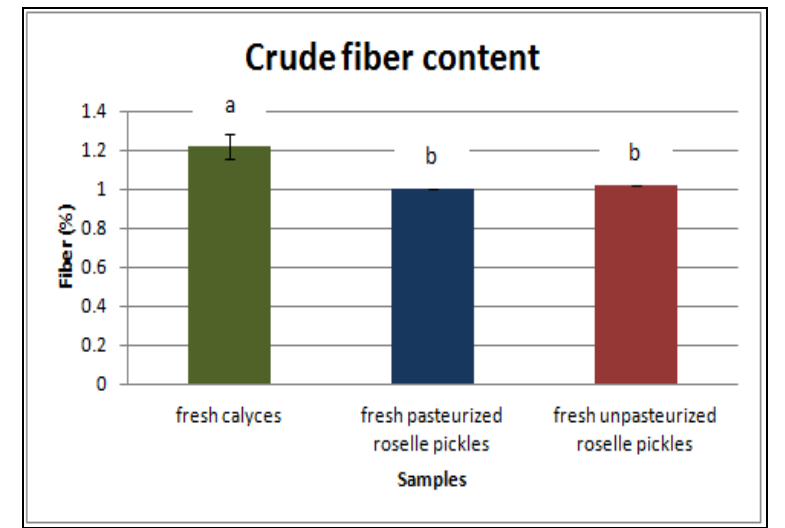

Fig. 10(a): Crude fiber content of roselle and fresh pickles

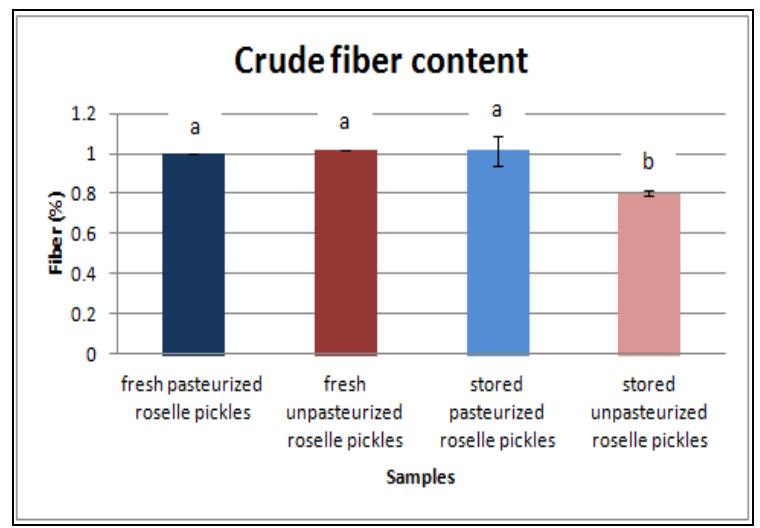

Fig. 10(b): Crude fiber content of fresh and stored pickles

\section{Protein}

* Means with the same letter are not significantly different $(p>0.05)$

There was no significant different in protein content between fresh calyces and fresh pickles (Fig. 11(a)). Protein content in fresh roselle was 1.145g/100g (Musa et al. 2006). Fig. 11(b) shows significant reduction of protein in stored pickles for both pasteurized and unpasteurized pickles as compared to their fresh pickles respectively. This might due to protein denaturation by acid (Chang, 2003). 


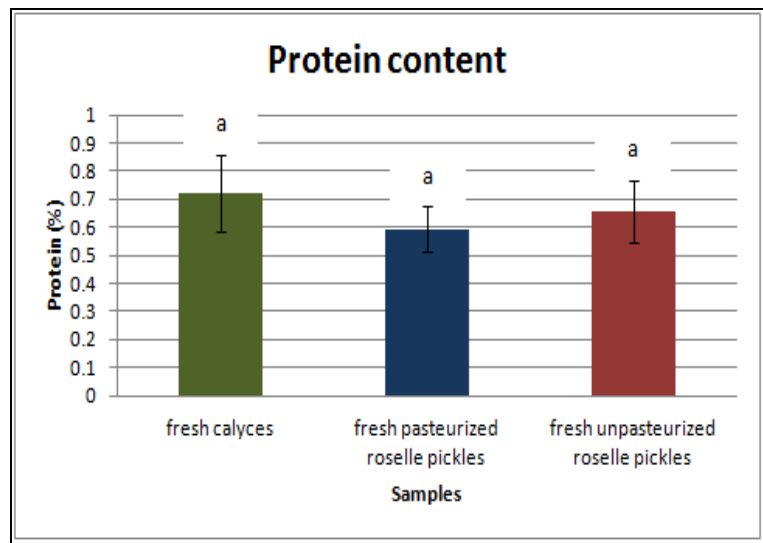

Fig. 11(a): Protein content of roselle and fresh pickles

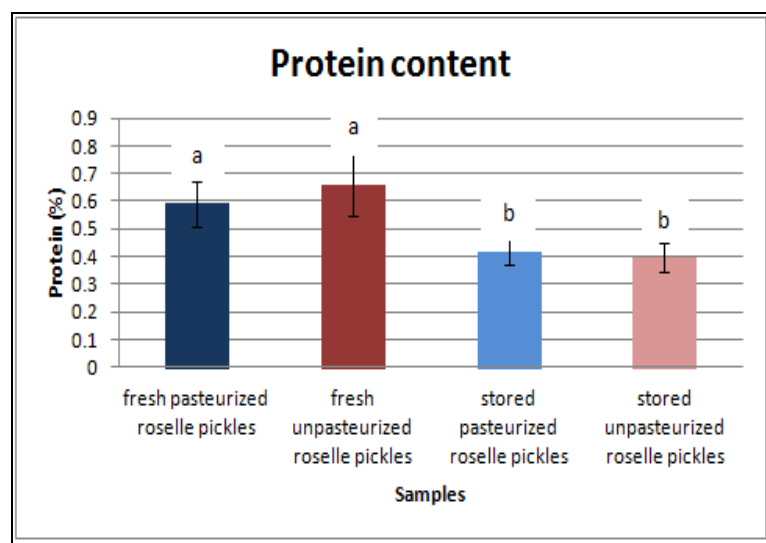

Fig. 11(b): Protein content of fresh and stored pickles

3.9

* Means with the same letter are not significantly different $(\mathrm{p}>0.05)$

Energy

No significant different was observed between fresh calyces and fresh pickles (Fig. 12(a)). The addition of sugar will affect the total carbohydrate content (Barrett, 1993). Fig. 12(b) shows that there were significant differences between fresh and stored unpasteurized pickles which might be due to some carbohydrate were broken down by bacteria.

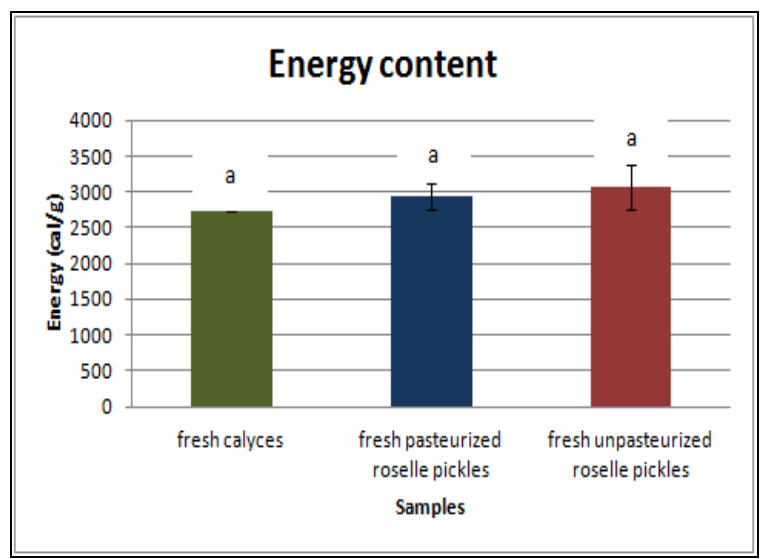

Fig. 12(a): Energy content of roselle and fresh pickles

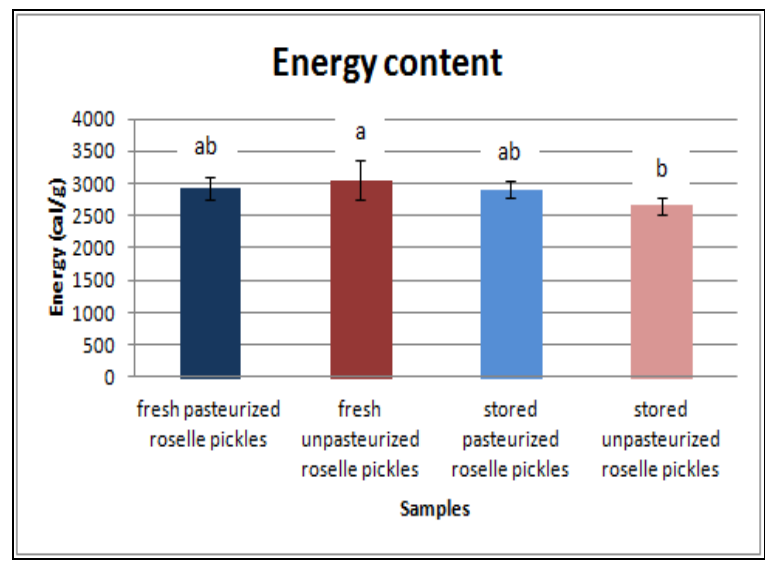

Fig. 12(b): Energy content of fresh and stored pickles

* Means with the same letter are not significantly different $(\mathrm{p}>0.05)$

\subsection{Microbiological properties}

Microbes found in fresh calyces and in fresh unpasteurized pickles. However, no microbes were found in the other pickles (Fig. 13). Microbes in fresh unpasteurized pickle were able to adapt to the low acid environment just for a short period of time. Satisfactory microbial quality for standard plate count in ready-toeat (RTE) food is $<10^{4} \mathrm{CFU} / \mathrm{g}$. Coliforms were found in fresh calyces. However no coliforms were found in the pickles (Fig. 14). This is due to high sugar and acidic environment that unable coliforms to live. Satisfactory microbial quality of E. coli in RTE food is $<10^{3} \mathrm{CFU} / \mathrm{g}$. This showed that pasteurized and unpasteurized pickles were safe for consumption. 


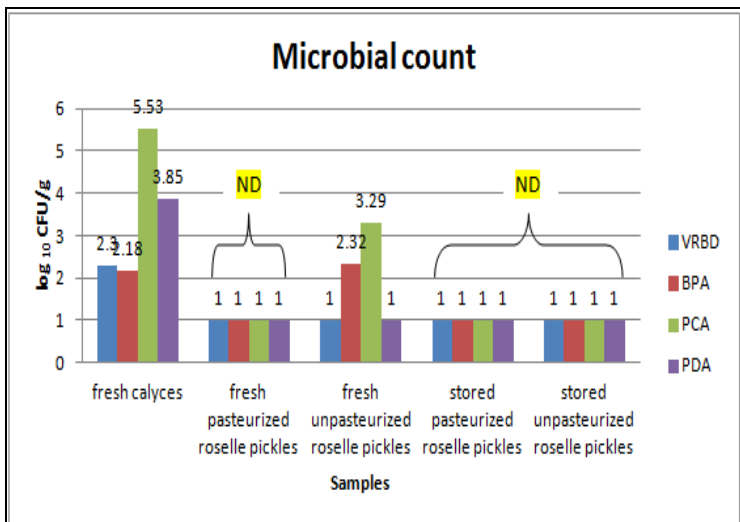

Fig. 13: Microbial count $(\mathrm{VRBD}=$

Enterobacteriaceae count, $\mathrm{BPA}=$ Staphylococcus aureus count, $\mathrm{PCA}=$ Aerobic Plate count; \& PDA=

Yeast and Mould count)

* ND: Not detected for microbes $<10 \mathrm{CFU} / \mathrm{g}$

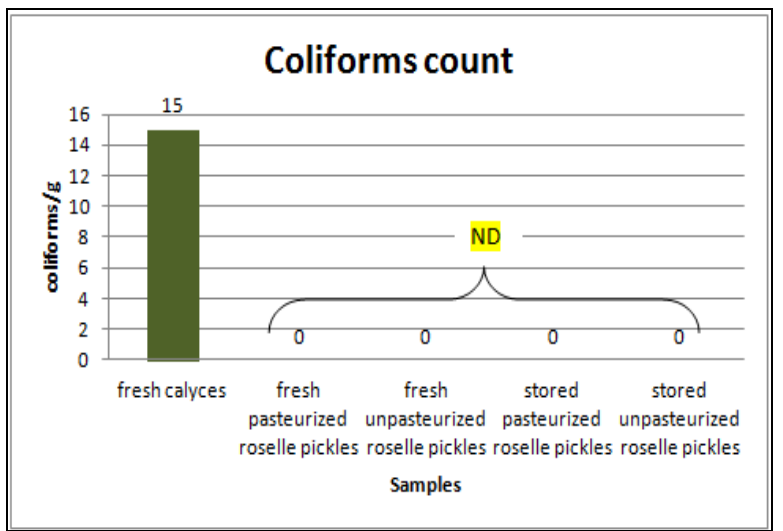

Fig. 14: Coliforms content using MPN method

$*$ ND: Not detected for microbes $<3$ coliforms $/ g$

\section{Conclusion}

The formulation using $50{ }^{\circ}$ Brix of sugar and $0.5 \%$ of acetic acid was selected as the most acceptable formula based on the sensory evaluation and texture analysis. In terms of microbiological properties of pasteurized and unpasteurized pickles, for both stored and fresh pickles they were all safe for consumption. Since pasteurized roselle pickles did not have much difference in physico-chemical and microbiological properties compared to unpasteurized roselle pickles, therefore the pasteurization process is not a necessary step in the production of roselle pickles.

\section{Acknowledgements}

The authors would like to acknowledge the Research Management and Innovation Centre, UMT for the financial support through TBKP grant, all the staffs at Food Science Lab, Postharvest Technology Lab and Plant Research Lab, School of Food Science and Technology, UMT for their commitment and helping hands as well as Roselle Special Interest Group (RSIG) UMT for the support.

\section{References}

[1] Anon. 2007. Fact sheets for the small scale food entrepreneur. The Northeast Center for Food Entrepreneurship at the New York State Food Venture Center. Cornell University [online]. Available from: http://www.nysaes.cornel.edu/necfe/ [Accessed 10 May 2010].

[2] Association of Analytical Communities (AOAC). 2000. Official methods of analysis 17th ed. Washington, DC: Association of Official Analytical Chemists.

[3] Barrett. D.M. 1993. Pickling. Encyclopedia of Food Science, Food Technology and Nutrition. Academic Press. Pp. 4563-4566

[4] Bell, C., Neaves, P., Williams, A.P. 2005. Food Microbiology and Laboratory Practice. United Kingdom. Blackwell Science. Pp. $18-29$.

[5] Castaneda-Ovando, A., Pacheco-Hernandez, M.L., Paez-Hernandez. M.E., Rodriguez, J.A. and Galan-Vidal. C.A. 2009. Chemical studies of anthocyanin: A review. Food Chemistry 113:859-871

[6] Chang, K.C.S. 2003. Protein Analysis. In: Suzanne,N.S. Food Analysis. $3^{\text {rd }}$ ed. Springer Science Business Media, Inc. Pp. 131-142.

[7] Etchells, J.L. and Jones, I.D. 1944. Procedure for Pasteurizing Pickle Products. Glass Packer.

[8] Food Regulation, Malaysia. 1985. International Law Book Service. [online]. Available from: www.malaysialawbooks.com. [Accessed 10 May 2010]

[9] Gu, Y.S., Howard, L.R. and Wagner, A.B. 1999. Physicochemical factors affecting firmness of pasteurized jalapeno pepper rings. Journal of Food Quality. 22:619-629.

[10] Hui, Y.H. 2004. Pickle Manufacturing in the United States: Quality Assurance and Establishment Inspection. In: Hui, Y.H., Ghazala, S., Graham, D.M., Murrell, K. D., and Nip, W. K. Handbook of Vegetables Preservation and Processing. Dekker. Pp.231250 .

[11] Jagota, S.K. and Dani, H.M. 1982. A new calorimetric technique for the estimation of vitamin C using folin phenol reagent. Analytical Biochemistry. 127:178-182.

[12] Lau, M.H. and Tang, J. 2002. Pasteurization of Pickled Asparagus using 915 MHz Microwaves. Journal of Food Engineering 51: 283-290.

[13] Muhamed, R., Fernandez, J., Pineda, M. And Aguilar, M. 2007. Roselle (Hibiscus sabdariffa) Seed oil is a Rich Source of $\gamma-$ Tocopherol. Institute of Food Technology 72:3:207-211.

[14] Musa, Y., Engku, I.E.A., and Yahaya, H. 2006. Teknologi Penanaman Rosel. Institute Penyelidikan dan Kemajuan Pertanian Malaysia (MARDI) Edisi pertama.

[15] Nasution, Z., Lai, B.K.K., Lani, M.N., and Ibrahim, R., (2013) Effect of Anti-browning treatments on the physico-chemical characteristics and sensory acceptance of green roselle (Hibiscus sabdariffa L., 'UKMR-3') pickles. Acta Hort. 1012, ISHS 2013, pp. $467-472$. 
[16] Osman E.M. 1983. Effect of different Factors on the Extraction, Concentration and Stability of Color in Roselle Juice- A Suggested potential natural colourant for foods.

[17] Pacome, O.A., Bernard, D.N., Sekou, D., Joseph, D.A., David, N.J., Mongomake, K., and Hilaire, K.T. 2014. Phytochemical and antioxidant activity of Roselle ((Hibiscus sabdariffa L.,) petal extracts. Research Journal of Pharmaceutical, Biological and Chemical Science. Pp. 1453

[18] Qi, Y., Chin, K.L., Fatemah, M., Mila, B. and Janet, G. 2005. Biological Characteristics, Nutritional and Medicinal Value of Roselle, Hibiscus Sabdariffa. Urban Forestry Natural Resources and Environment No. 604.

[19] Rodrigo, M. And Alvarruiz. A. 1988. The Influence of Fermentation and Pasteurization on the Texture of Cucumber Pickles. Journal of Food Engineering 113-125.

[20] Tucker, G.S. 2008. Food Biodeterioration and Preservation. Oxford: Blackwell Publication.

[21] Tassou, C.C., Panagou, E.Z. and Katsaboxakis, K.Z. 2002. Microbiological and Physicochemical Changes of Naturally Black Olives Fermented at Different Temperature and $\mathrm{NaCl}$ levels in the brines. Food Microbiology 19:605-615.

[22] Valdez-Fragoso, A., Saenz-Hernandez, C. M., Welti-Chanes, J. and Mujica-Paz, H. 2009. Cherry pepper pickling: Mass Transport and Firmness Parameters and Stability Indicators. Journal of Food Engineering 95:648-655.

[23] Wong, P.K., Salmah, Y. Ghazali, H.M. and Che, M. 2002. Physico-chemical characteristics of Roselle (Hibiscus sabdariffa L.). Nutrition and Food Science Vol 32(2):68-73. 